\title{
Control over the Process of Thermo-Oxidative Degradation of Polymers in a Solution
}

\author{
Igor Anatolyevich Khaustov ${ }^{1}$, Vitaly Ksenofontovich Bitukov ${ }^{1}$, Sergey Germanovich Tikhomirov ${ }^{1}$, Anatoly \\ Anatolyevich Khvostov ${ }^{1} \&$ Alexei Petrovich Popov ${ }^{1}$ \\ ${ }^{1}$ Voronezh State University of Engineering Technologies, 19, Revolutsii ave., 394036, Russia \\ Correspondence: Vitaly Ksenofontovich Bitukov, Voronezh State University of Engineering Technologies, 19, \\ Revolutsii ave., 394036, Russia.
}

Received: January 9, 2015

Accepted: January 19, $2015 \quad$ Online Published: June 25, 2015

doi:10.5539/mas.v9n8p128

URL: http://dx.doi.org/10.5539/mas.v9n3p128

\begin{abstract}
The article discusses the process of low molecular rubber synthesis by the method of thermo-oxidative degradation as a controlled object. It was found that the control parameters affecting the degradation rate are the following: concentration of reaction initiator, temperature and mass concentration of the polymer. The main control parameters are the following: degree of degradation, quality of the resulting polymer and time of reaction. It was found that for effective control the process temperature and concentration of the initiator are to be stabilized in the vicinity of the predetermined value, and mass concentration is determined by dosage of initial components. In this case, the kinetics of the degradation process can be described as a linear function of time. I.e., the degree of degradation is linearly related to duration of reaction. Then, defining the initial quality of the polymer (its average molecular weight), the degradation process is performed till the time the predetermined value of degradation is reached.

Since the initiator is consumed during the degradation, in order to stabilize its concentration, it is proposed to add the initiator into the reaction medium. We obtained a mathematical description that describes the kinetics of the process during continuous and divided feeding of the initiator, and dependency for calculating initiator feed rate. It has been shown that if the initiator is fed in a divided manner, linearity of degradation kinetics over time is ensured, which simplifies the technology of the process.

Parameters of the approximating linear dependence of the kinetics of degradation have been determined. It has been shown that, even at the initial stage, the kinetics of degradation steadily tends to the linear asymptote. The asymptote's tilt angle depends on the constant of degradation rate (and consequently in the temperature of reaction) and on the initial concentration of the initiator. Degradation kinetics offset by the Y-axis depends on the initial molar concentration of the polymer. Thus, it is possible to control degradation rate by adjusting initial polymer concentration.
\end{abstract}

Keywords: thermal oxidative degradation of polymers, control system

\section{Introduction}

One of the promising methods of obtaining low molecular polymers with adjustable molecular weight is the thermo-oxidative degradation. Such polymers are used in the national economy for manufacturing adhesive compositions, anti-corrosion coatings, polymer-and-bitumen compositions, construction sealants, etc.

The process of obtaining low molecular polymers on destruction on the basis of high-molecular polymers generally consists of the following basic steps: loading components of the reaction (solvent, polymer); heating the reaction mass to the predetermined temperature and dissolution of the polymer; loading initiator; degradation to the predetermined degree of polymer degradation; loading inhibitor - end of degradation; cooling of the reaction mass; and drying and recovering resulting low molecular polymer. The main stage of the process in question is the destruction process, since it is at this stage where the main indicators of product quality reformed (average molecular weight of the polymer and the polydispersity index).

In this context, the objectives of studying the system for controlling degradation process are the following:

- adjusting the degree of polymer degradation, which is a variable and depends on what kind of polymer the technology should produce, and in what area it will be used; 
- calculation of controlling actions that would allow to achieve the desired degree of degradation in the period of reaction defined in the technology.

Controlling actions that affect the behavior of the degradation process include the following parameters: temperature of the degradation process, concentration (volume ratio) of the polymer in the solution, concentration of the initiator of degradation (in moles), the ratio of decomposer and polymer concentrations in the reaction mixture, intensity of bubbling reaction mixture with atmospheric air; and feed rate of the initiator. Block diagram of thecontrolling object is shown in Figure 1.

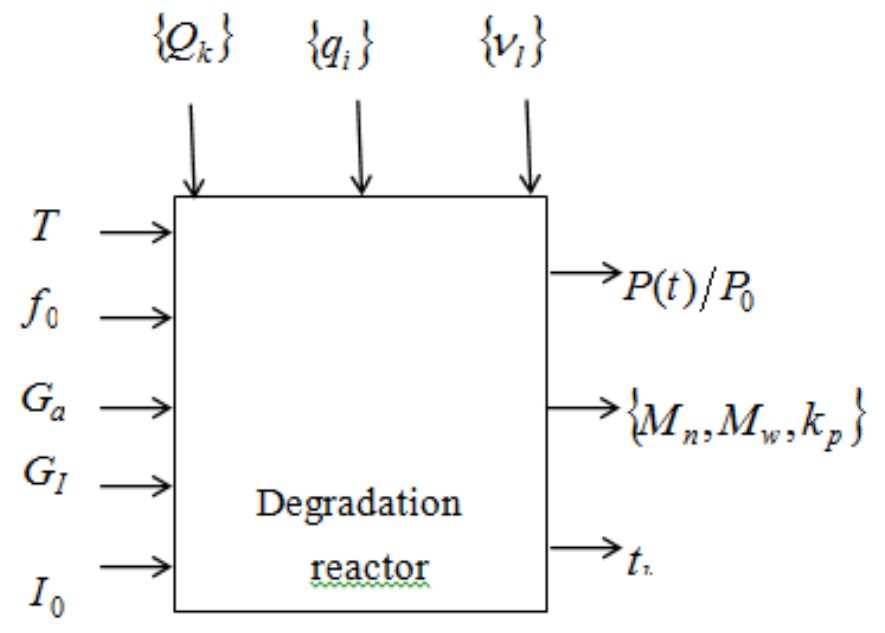

Figure 1. Block diagram of the controlling object

In Fig. $1 P(t) / P_{0}$ is the degree of polymer degradation; $\left\{M_{n}, M_{w}, k_{p}\right\}$ are parameters of polymer quality (numerical-average and weight-average molecular weight of the polymer, polydispersity index); $P_{0}, P(t)$ is the initial and the current concentration of the polymer [mole/l]; $I_{0}$ is the initial concentration of the initiator [mole/l]; $f_{0}$ is mass concentration of the polymer, $[\mathrm{kg} / 1] ; T$ is the temperature of the reactor $\left[{ }^{\circ} \mathrm{C}\right] ; t_{k}$ is degradation time [min]; $G_{a}, G_{I}$ are feed rates of air and initiator into the reactor $[\mathrm{kg} / \mathrm{min}] ;\left\{q_{i}\right\}$ are thermal parameters (heat capacity, heat transfer coefficient, etc.); $\left\{v_{l}\right\}$ are physical and rheological properties of the reaction mixture (viscosity, density, concentration of substances formed during secondary processes, etc.); and $\left\{Q_{k}\right\}$ is the set that characterizes thermal agitations (heat generation due to the reaction, mixing, temperature of environment, coolant, etc.).

Resolution of these tasks is directly related to studying kinetics of the controlled decomposition, including mathematical modeling.

The problem of studying degradation of polymers by simulation is described in many works of both domestic (Berlin et al., 1978; Bryk, 1989; Koptelov and Milekhin, 2012) and foreign researchers (Ivanova et al., 2012; Browarzik and Koch, 1996; Ziff and McGrady, 1986). Studying of the polymer degradation process in a solution by modeling is described in a relatively small number of studies (Sivalingam and Madras, 2004; Sterling et al., 2001).

\section{Method}

For the purpose of synthesis and studying of control systems, in work (Tikhomirov et al., 2013) kinetic equations were obtained in the form of analytic dependencies that describe the dynamics of component changes in the reaction mixture - concentration of polymer, process initiator and decomposition agent.

In order to describe the kinetics of polymer thermal oxidative degradation in the solution, the following assumption was made - in the ideal case, one mole of the initiator produces 2 moles of the decomposition agent, and reaction of one mole of the decomposition agent with one mode of the polymer produces 2 moles of the polymer, i.e., the following kinetic scheme is used:

$$
\begin{gathered}
\mathrm{I} \stackrel{\mathrm{k} 2}{\rightarrow} 2 \mathrm{D} \\
\mathrm{D}+\mathrm{P} \stackrel{\mathrm{k} 1}{\rightarrow} 2 \mathrm{P}
\end{gathered}
$$


In modeling the process, the following assumptions were used:

1. Due to breaking of double bonds and elementary act of decomposition, one molecule of the decomposition agent is spent for formation of two polymer macro-molecules with a hydroxy end group on one of the two macro molecules of the polymer.

2. Both macro-molecules formed during the reaction of degradation belong to the same class of macromolecules as the original macro-molecule of the polymer, i.e. $\mathrm{P}^{*} \equiv \mathrm{P}$.

3. The degradation rate constant does not depend on the length of the macromolecule.

4. Exhaustion of the decomposition agent is described by a first-order reaction, whose rate is independent of temperature and pressure in the reactor.

5. The degradation rate constant is many times greater than the constant speed of deactivation of the decomposing agent.

6. In the degradation reactor, intensive stirring occurs.

The kinetics of thermal oxidative degradation of the polymer in the solution in accordance with the kinetic scheme and assumptions is described in general by the system of equations:

$$
\begin{gathered}
\frac{d I(t)}{d t}=-2 k_{2} I(t) . \\
\frac{d D(t)}{d t}=2 k_{2} I(t)-k_{1} P(t) D(t) . \\
\frac{d P(t)}{d t}=k_{1} P(t) D(t) . \\
P(0)=P_{0}, D(0)=0, I(0)=I_{0},
\end{gathered}
$$

where $D(t)$ is concentration of the decomposing agent, [mole/l]; $k_{2}$ is the constant of formation rate of the decomposing agent, [1/min]; $k_{1}$ is the constant of decomposition rate, [1/(mole $\left.\left.\cdot \min \right)\right]$.

The expressions describe the kinetics of change in concentration of the initiator, the polymer and the decomposition agent in the volume of the reaction mixture during the reaction in isothermal conditions provided that the process is performed in a batch reactor with constant intensive stirring and bubbling with atmospheric air.

The influence of the reaction mass temperature on the rate of chemical degradation is described by the Arrhenius equation

$$
k_{j}=k_{0 j} \cdot \exp \left(-E_{j} / R T\right)
$$

where $R=8.315$ is the universal gas constant, $\left[\mathrm{J} /\left(\right.\right.$ mole $\left.\left.^{\circ} \mathrm{K}\right)\right] ; k_{0 j}$ is the pre-exponential constant, dimensions

correspond to $k_{j} ; E_{j}$ is the energy of activation [J/mole $] ; j=\overline{1,2}$.

For equation (5), estimates of activation energies were obtained for chemical reactions and pre-exponential constants: $k_{01}=7.96 \cdot 1013[1 /(\mathrm{mole} \cdot \mathrm{min})] ; \quad k_{02}=2.3 \cdot 1010[1 / \mathrm{min}] ; \quad E_{1}=81.8[\mathrm{KJ} / \mathrm{mole}] ; \quad E_{2}=86.4$ $[\mathrm{KJ} / \mathrm{mole}]$. According to the literature, the value of activation energy $E_{2}=83.7[\mathrm{KJ} / \mathrm{mole}]$ (Geller et al., 1996), which confirms veracity of the estimates.

Adjustment of the reaction temperature is an effective way to control the rate of chemical degradation. As it follows from Fig. 2, the reaction rate increases exponentially with increasing temperature. However, at $70{ }^{\circ} \mathrm{C}$, the reverse process, jellification is observed, in spite of introduction of antioxidants. This can be seen in Figure 3 and 4. After four hours, according to the experimental data, the degradation rate decreases, as compared to the calculated theoretical concentration values (Figure 3). This corresponds to increasing of jellification rate after 4 hours of degradation (Figure 4). 


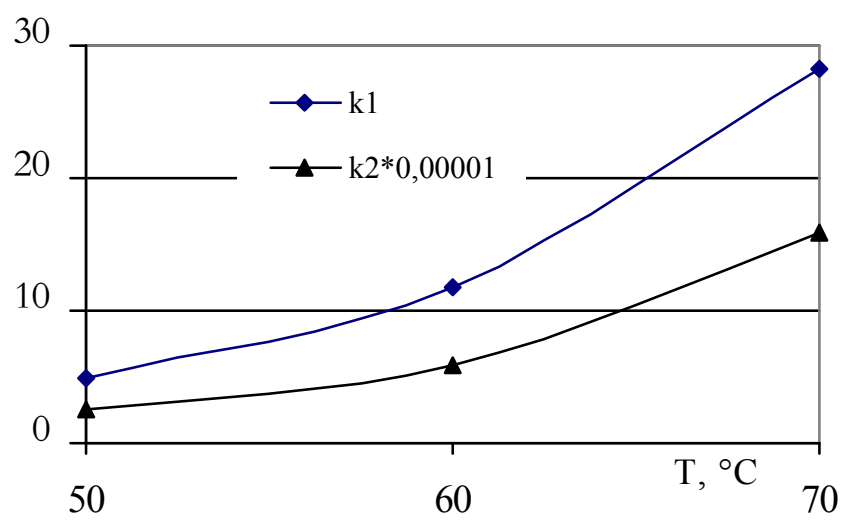

Figure 2. Influence of reaction temperature on degradation rate

The difference between experimental and calculated data at $70{ }^{\circ} \mathrm{C}$ is explained by the fact that at higher temperatures, the intensity of secondary processes increases - polymer chains recombination reaction, which leads to cross-linking of the macromolecules, and as a consequence, to reducing their concentrations. In this regard, introduction of antioxidants cannot completely prevent jellification.

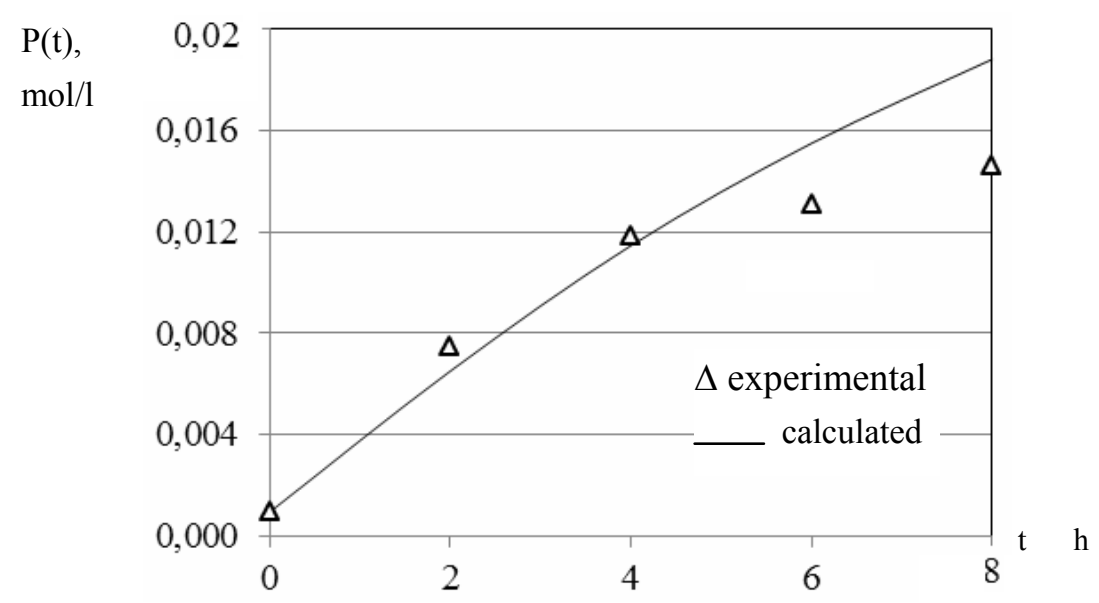

Figure 3. The dynamics of concentration change during polymer degradation, $T=70{ }^{\circ} \mathrm{C}$

It is clear that at high temperatures, the rate of formation of gels increases. In this regard, for performing the chemical degradation with maximum efficiency it is reasonable to use stabilization of the maximum temperature. In this case jellification does not occur, or can be prevented.

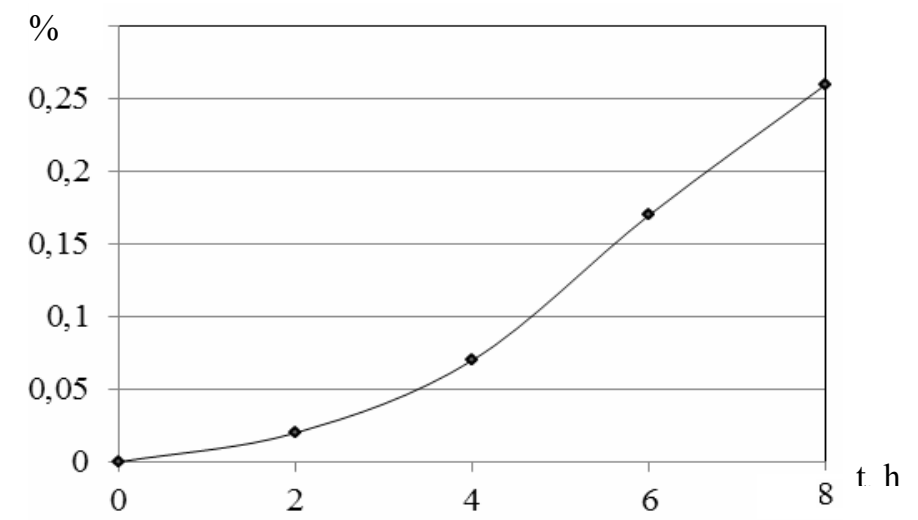

Figure 4. Dynamics of peroxide compounds formation during degradation, $T=70{ }^{\circ} \mathrm{C}$ 
The possibility of controlling the degradation process by adjusting the rate of bubbling of the reaction mass with the atmospheric air is limited by the rate of air dissolution in the solution and by the limit of its saturation with oxygen. In this case, air supply into the reaction zone with the maximum efficiency should be ensured, i.e. $G_{a}>G_{\max }(t)$, where $G_{\max }(t)$ is the maximum rate of feeding air into the reactor, which ensures saturation of the solution with oxygen, $[\mathrm{kg} / \mathrm{min}]$.

Increasing the mass concentration of the polymer in the solution leads to accelerated degradation process. However, at the same time, as experimental studies show, the rate of jellification increases, since with increasing concentration of the solution, the probability of polymer molecules recombination increases as well. The permissible concentration of polymer of $10 \%$ has been found experimentally; in case of a higher concentration, active jellification starts.

The influence of the initial charge of initiator and the possibility to control degradation rate by adjusting concentration of the initiator has been described in the mathematical model (1) - (3).

\section{Results}

\subsection{Control on the Basis of Continuous Dosing of the Initiator}

Suppose the initiator is continuously introduced into the reaction zone at the rate of $G_{I}(t) \quad[\mathrm{kg} / \mathrm{min}]$, so that the concentration of the initiator in the reaction mixture is maintained constant during the entire process of degradation, i.e.

$$
I(t)=I_{0}=\text { const } .
$$

Let us find the solution (1)-(3) by introducing an assumption that the volume of the reaction mass slightly increases due to additional dosing of initiator into the reactor, i.e. $V_{0}>>V_{I}$.

In this case, the change in concentration of the reactants caused by increase in the volume is not considered, and the initiator feed rate into the reactor is calculated basing on conditions $-k_{2} I(t)+\frac{G_{I}(t)}{V(t) M_{I}}=0$, i.e.

$$
G_{I}(t)=k_{2} I_{0} V_{0} M_{I}
$$

where $M_{I}$ is the molar mass of the initiator $[\mathrm{kg} / \mathrm{mole}]$.

Then the initial system of equations is reduced to

$$
\begin{gathered}
\frac{d D(t)}{d t}=2 k_{2} I_{0}-k_{1} P(t) D(t) . \\
\frac{d P(t)}{d t}=k_{1} P(t) D(t) .
\end{gathered}
$$

The resolution of a system of equations (8) - (9) using initial conditions (4) is obtained in form

$$
\begin{gathered}
P(t)=\frac{\varphi(t)}{k_{1} \psi(t)+1 / P_{0}} . \\
D(t)=P_{0}+2 k_{2} \cdot I_{0} \cdot t-P(t) .
\end{gathered}
$$

where $\psi(t)=\int_{0}^{t} e^{k_{1} \cdot P_{0} \cdot \tau+2 k_{1} \cdot k_{2} \cdot I_{0} \cdot \tau^{2}} d \tau, \varphi(t)=e^{k_{1} \cdot P_{0} \cdot t+2 k_{1} \cdot k_{2} \cdot I_{0} \cdot t^{2}}$.

Figure 5 shows the variants of polymer degradation for different initial conditions of equations calculation (10). Curve 1 corresponds to the reaction flow with the initial starting dosage. Curve 2 - the initial concentration of the polymer is increased 10 times. Curve 3 - the initial concentration of the initiator is increased 5 times. In all 3 cases, the initial concentration of initiator is maintained constant. 


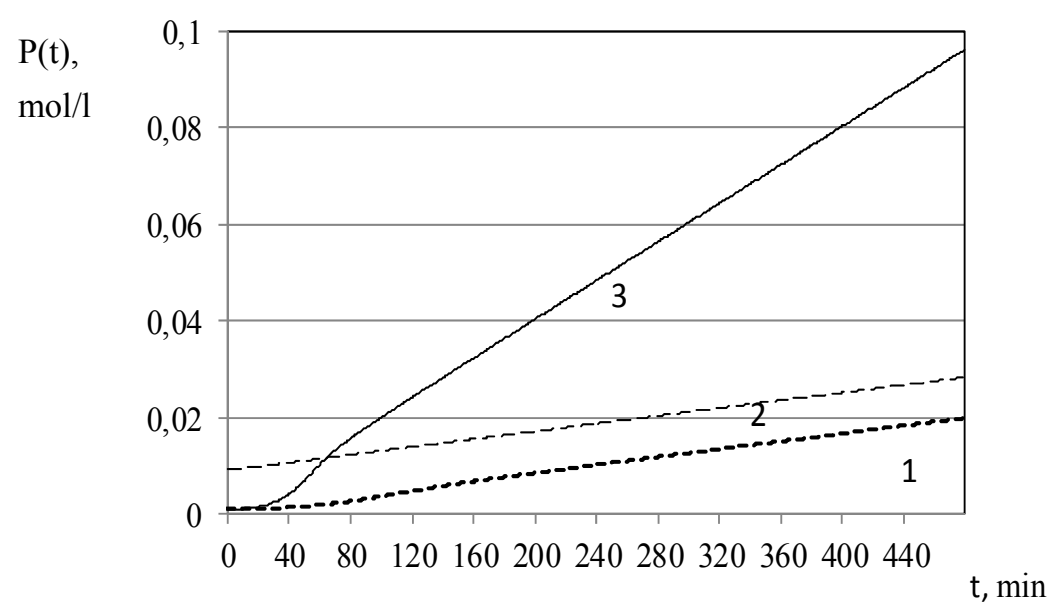

Figure 5. The kinetics of polymer degradation with $I(t)=I_{0}$

As can be seen from Fig. 5, if the concentration of the initiator stabilizes regardless of the original properties of the polymer (initial concentration of the polymer $P_{0}$ and, consequently, its initial average molecular weight), the function of polymer concentration to time tends to be linear. That is, changes in polymer concentration in this case are proportional to the time of degradation. Since $P_{0}$ is a constant and is determined by the quality of initial polymer, the degree of degradation is also close to the linear law of change with time.

Besides, change of the initial concentration of the polymer proportionally influences the offset of graphs along the Y-axis (curve 2), and change of the initiator concentration is proportional to the angle of curve inclination (curve 3), i.e., to degradation rate. So, the graph of changes in polymer concentration has a slant asymptote expressed by a linear function

$$
P_{\text {lin }}(t)=a_{0}+a_{1} \cdot t
$$

where $a_{0}, a_{1}$ are coefficients of linear dependence, which are functions of the initial concentrations of the reactants and the reaction rate constants.

To find $a_{1}$, let us consider the finite limit

$$
a_{1}=\lim _{t \rightarrow \infty}\left(\frac{P(t)}{t}\right)=\lim _{t \rightarrow \infty}\left[\frac{e^{k_{1} \cdot P_{0} \cdot t+2 k_{1} \cdot k_{2} \cdot I_{0} \cdot t^{2}}}{\left(k_{1}^{t} e_{0}^{k_{1} \cdot P_{0} \cdot \tau+2 k_{1} \cdot k_{2} \cdot I_{0} \cdot \tau^{2}} d \tau+1 / P_{0}\right)}\right] .
$$

The finite limit (13) has uncertainty in form $[\infty / \infty]$, so in order to find it, the L'Hôpital's rule is used,

$$
a_{1}=\lim _{t \rightarrow \infty}\left(\frac{P_{0}+4 \cdot k_{2} \cdot I_{0} \cdot t}{t}\right)=4 \cdot k_{2} \cdot I_{0}
$$

Similarly, we obtain $a_{0}$, which is found from the condition

$$
a_{0}=\lim _{t \rightarrow \infty}\left(P(t)-a_{1} \cdot t\right)=P_{0} .
$$

Figure 6. shows the kinetics of degradation at various initial conditions and its approximation by expression (12). As it can be seen from the figure, the kinetics of degradation even at low $t$ takes the form of its asymptote's graph (12). 


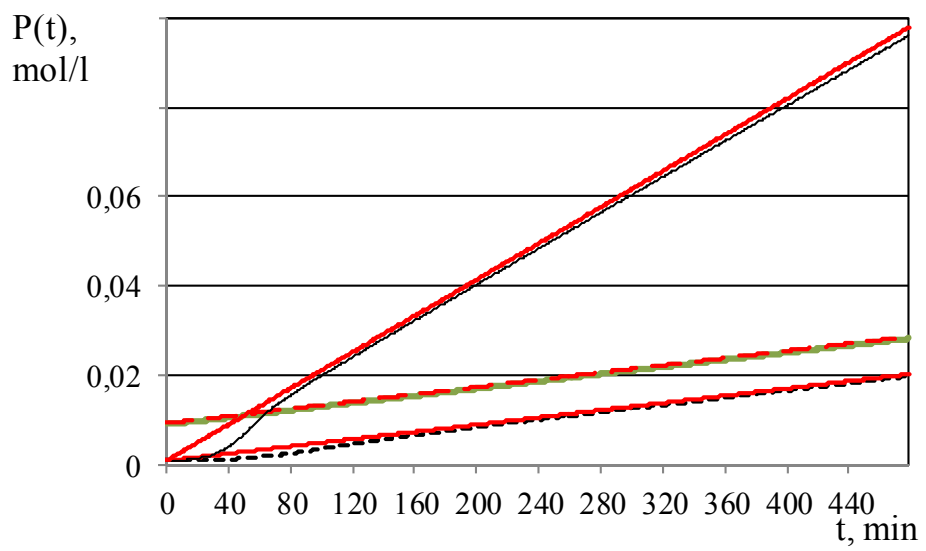

Figure 6. Linear approximation of the kinetics of polymer degradation according to (12) with $I(t)=I_{0}$

Calculations show that due to continuous dosing of initiator for 8 hours of degradation, the volume of reaction mass increases by $0.5-3.5 \%$ for the temperature of reaction between $50^{\circ} \mathrm{C}$ and $70^{\circ} \mathrm{C}$.

These data confirm validity of using equations (8) - (9) for an approximated description of the degradation kinetics with the initiator continuously fed into the reaction medium.

\subsection{Control on the Basis of Partial Addition of the Initiator}

However, in industrial production conditions it is rater hard to ensure continuous addition of the initiator with high accuracy. It should be noted that due to sensitivity of the degradation kinetics to concentration of the initiator, minor deviations caused by metering accuracy can significantly affect the kinetics of degradation. For example, for the reaction mass of 1 ton with the initial starting concentrations of reaction components, initiator dosage at a rate of 7 to $50 \mathrm{~g} / \mathrm{min}$ should be ensured.

Much more convenient in terms of technology of process implementation is partial addition. Addition is made at regular intervals in equal batches.

The dose is calculated according to the formula

$$
V_{d}=I_{0} V_{0} M_{I}\left(1-e^{-k_{2} t_{d}}\right),
$$

where $t_{d}$ is the period of partial addition of the initiator in minutes.

Figure 7 shows comparison of calculated degradation kinetics between continuous and partial feeding of the initiator at the temperature of the reaction mass $70^{\circ} \mathrm{C}$. Curve 1 is the graph of polymer concentration in case of continuous addition of the initiator, curve 2 is the fractionality of addition of the initiator for 1 hour, curve 3 - for 2 hours, curve 4 - for 3 hours.

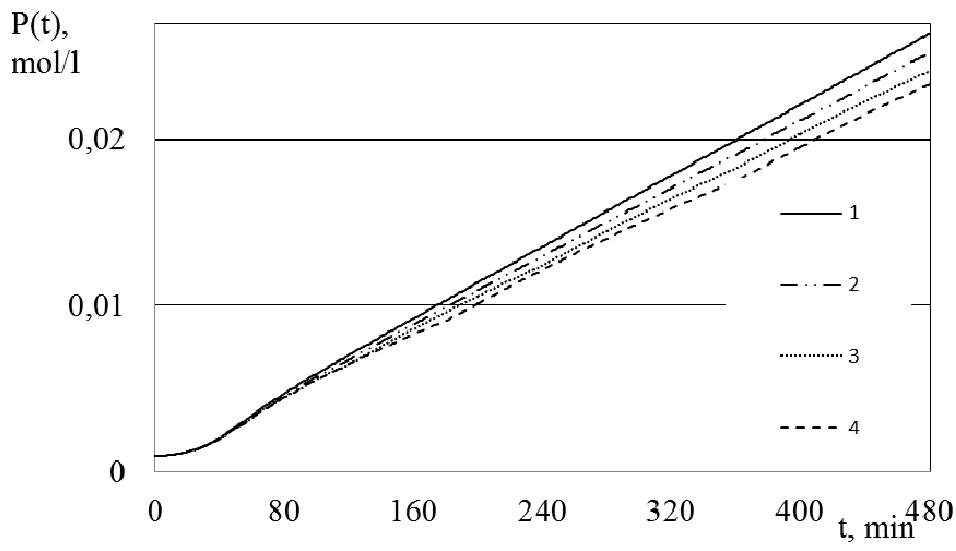

Figure 7. Comparison of degradation kinetics in case of continuous and partial addition of the initiator 
As it can be seen from the figure, in case of partial addition, the linear form of the degradation reaction kinetics is maintained. Besides, the deviation of polymer concentration in case of continuous and partial addition of the initiator is insignificant. Concentration ratio of the polymer $P k_{d} / P k_{n}$ with initial starting dosage is presented in Table 1 (position 1). $P k_{n}$ and $P k_{d}$ are polymer concentrations after the degradation process with continuous and fractional addition of the initiator, respectively, mole/l.

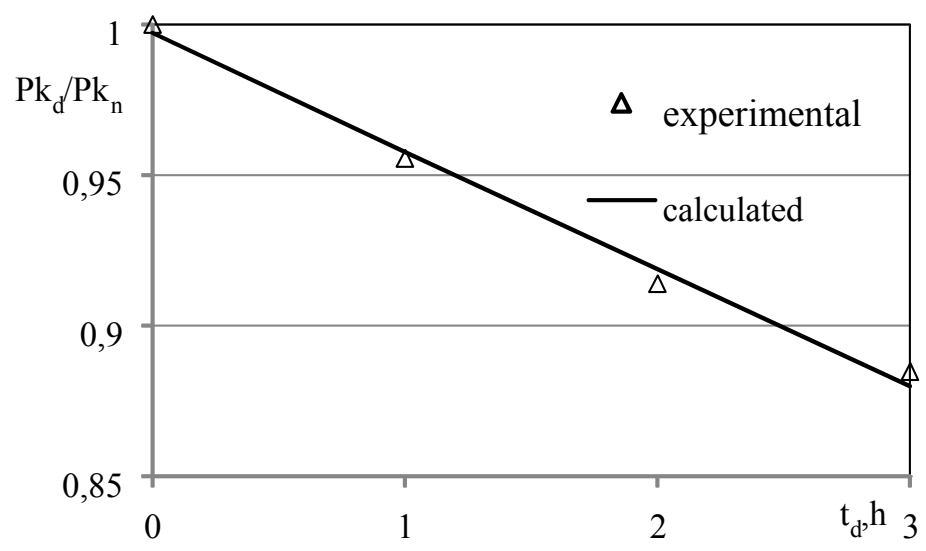

Figure 8. Dependence of ratio $P k_{d} / P k_{n}$ on the period of partial addition

Figure 8 shows that dependence of the $P k_{d} / P k_{n}$ ratio on the period of partial addition of the initiator can be described by a linear dependence of form

$$
P k_{d} / P k_{n}\left(t_{d}\right)=b_{0}+b_{1} t_{d}
$$

To assess the influence of initial dosage of the initiator and the initial polymer concentration, numerical experiments were performed. With that, initial concentration of the initiator and polymer were decreased and increased two-fold. The results of the study are shown in Table 1. 
Table 1.

\begin{tabular}{lllllll}
\hline Position & Terms of numerical experiment & \multicolumn{3}{c}{$P k_{d} / P k_{n}$} \\
& & \multicolumn{3}{c}{ Coefficients (17) } \\
\cline { 3 - 7 } & & $t_{d}=1 \mathrm{~h}$. & $t_{d}=2 \mathrm{~h}$. & $t_{d}=3 \mathrm{~h}$. & $b_{0}$ & $b_{1}$ \\
1. & $I_{0} \cdot P_{0}$ & 0.956 & 0.914 & 0.885 & 0.997 & -0.039 \\
2. & $2 I_{0} \cdot P_{0}$ & 0.955 & 0.914 & 0.883 & 0.997 & -0.039 \\
3. & $0,5 I_{0} \cdot P_{0}$ & 0.957 & 0.917 & 0.886 & 0.997 & -0.037 \\
4. & $I_{0} \cdot 2 P_{0}$ & 0.957 & 0.917 & 0.889 & 0.997 & -0.037 \\
5. & $I_{0} \cdot 0,5 P_{0}$ & 0.957 & 0.913 & 0.883 & 0.997 & -0.035 \\
\hline
\end{tabular}

The results show that the influence of initial concentration of the initiator and polymer on the deviation of final concentrations of the polymer in case of continuous and partial addition of the initiator can be neglected.

Influence of temperature of the reaction mass on the $P k_{d} / P k_{n}$ ratio is shown in Table 2.

Table 2.

\begin{tabular}{lllllll}
\hline Position & Terms of numerical experiment & \multicolumn{3}{c}{$P k_{d} / P k_{n}$} \\
& & \multicolumn{3}{c}{ Coefficients (17) } \\
\cline { 3 - 7 } & & $t_{d}=1 \mathrm{~h}$. & $t_{d}=2 \mathrm{~h}$. & $t_{d}=3 \mathrm{~h}$. & $b_{0}$ & $b_{1}$ \\
1. & $T=70^{\circ} \mathrm{C}, I_{0} P_{0}$ & 0.956 & 0.914 & 0.885 & 0.997 & -0.039 \\
2. & $T=60^{\circ} \mathrm{C}, I_{0} P_{0}$ & 0.984 & 0.969 & 0.957 & 0.99 & -0.015 \\
3. & $T=50^{\circ} \mathrm{C}, I_{0} P_{0}$ & 0.993 & 0.987 & 0.982 & 1 & -0.006 \\
\hline
\end{tabular}

As it can be seen in Table 2, with reaction temperature decreasing, the $P k_{d} / P k_{n}$ value-increases. Obviously, the temperature has little effect on $b_{0}$, and changing $b_{1}$ is approximated by linear dependence

$$
b_{1}(T)=c_{0}+c_{1} T \text {. }
$$

where $c_{0}, c_{1}$ are the empirical coefficients.

In view of the relationships obtained above (17) - (18), the kinetic equation of degradation, depending on the conditions of partial addition of the initiator into the reaction area and the temperature of the reaction mass, can be approximated by the expression

$$
\mathrm{P}(\mathrm{t})=\left(\mathrm{P}_{0}+4 \mathrm{k}_{2} \mathrm{I}_{0}\right) /\left(1+\mathrm{c}_{0} \mathrm{t}_{\mathrm{d}}+\mathrm{c}_{1} \mathrm{Tt}_{\mathrm{d}}\right)
$$

Fig. 9. shows comparison of the kinetics of polymer degradation at $70{ }^{\circ} \mathrm{C}$, under the condition of partial addition of the initiator without additional dosage. The initiator is partially added every 2 hours.

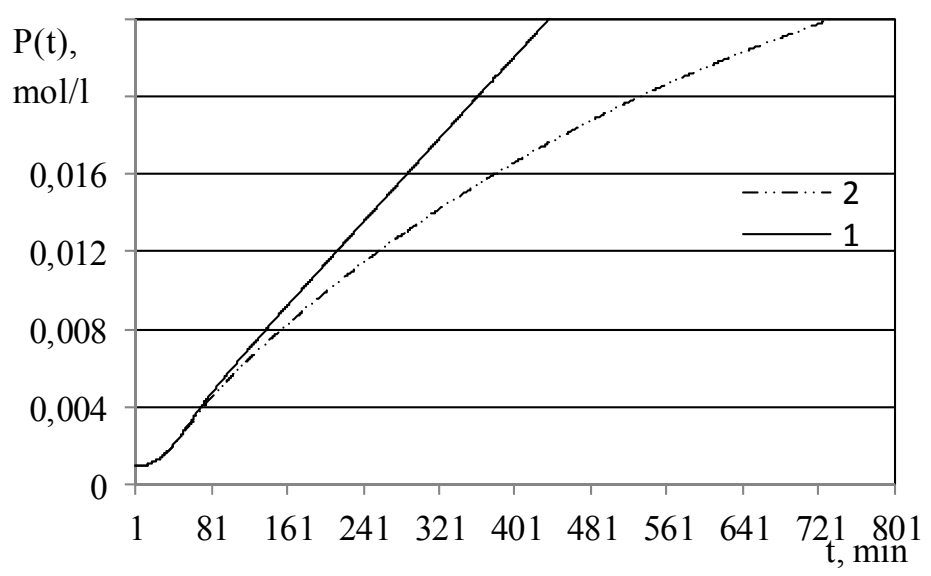

Figure 9. Comparison of the kinetics of uncontrolled degradation (single dosage of the initiator) and kinetics of degradation at fractional initiator 
In Fig. 9 curve 1 describes the kinetics of degradation in case of partial addition of the initiator, curve 2 describes the kinetics of uncontrolled degradation (single dosage of initiator is used). The advantage of controlled (or continuous) degradation with partial addition of the initiator is the fact that in the same initial conditions of the reaction, it is possible to significantly reduce the time of the process until the desired degree of degradation. As it can be seen from the figure, the response time is reduced more than 1.5 times. Besides, a controlled degradation makes it possible to perform predictable degradation according to the linear law as a function of time. I.e., the control parameter is the response time that is linearly associated with the predefined degree of degradation. In this case, it becomes possible to implement software control; it is only necessary to know the original quality of the polymer - its initial average molecular weight $M_{n}$ that is associated with the initial molar concentration of the polymer according to the formula $P_{0}=f_{0} / M_{n}$.

\section{Discussion}

The process of thermo-oxidative degradation of polymers in a solution is performed in the reactor using the periodical technology. Batch reactors are inefficient, but at the same time they are simple in design, require little auxiliary equipment, therefore, they are particularly suitable for experimental work for studying chemical kinetics. In industry they are commonly used in small-scale production and for the processing of relatively expensive chemicals. The common property of the polymer polymerization and degradation in a solution performed according to the periodic scheme in terms of production technology is their being not stationary. These processes are described by similar systems of differential equations, which make it possible to establish the relationship between the controlled settings and possible controlling influences.

An important technological task for batch processes of polymerization or degradation is the ensuring of the desired indicators of final polymer quality, such as concentrations of output products, average molecular weight, melt index, intrinsic viscosity of the polymer, degree of polymer degradation, etc. (Harish, 2011;-Bayzenberger and Sebastian, 1988).

For some polymerization processes (for example, during preparation of thermo elastoplasts), the main task of control, same as during polymer degradation, is obtaining polymers with predetermined average molecular weight $M_{n}$. Thus, the task of adjusting polydispersity $K_{p}$ of obtained products is not practically set, since in the first case the narrowness of molecular weight distribution (MWD) is achieved by using highly efficient initiating system, and using polymerization mechanism of anionic polymerization (Moiseev, 1985). In the second case, MWD constantly tends to the Flory distribution, and the polydispersity index tends to value 2 (Browarzik and Koch, 1996; 15 Kaminsky and Kuznetsov, 2012).

Methods of controlling batch reactors are mainly based on changing the reaction temperature or varying concentrations of added catalyst and monomer (Bayzenberger and Sebastian, 1988). For example, in (Cott and Macchieto, 1989) temperature adjustment during exothermic reaction in a batch reactor is described. Reactors are controlled by choosing the optimal temperature profiles due to chosen criterion of quality followed by using standard control algorithms with feedback providing support for the selected mode. Common way to control the temperature in batch reactors is the use of a regulator with variable structure (Shinskey and Weinstin, 1965; Liptak, 1986). In work (Gluett et al., 1985) the process temperature was controlled using an adaptive algorithm. In (Jutan and Uppal, 1984) control was calculated according to the mathematical model of the process with estimation of the amount of heat generated in the reactor at any given moment. Based on the mathematical model of the process, the control algorithm for heating the reaction mass and further stabilization of temperature and a possibility to control its use for controlling the exothermic batch reactor was discussed in (Kershenbraun and Kittisupakorn, 1994; Marroquin and Luyben, 1973) and in (Cott and Macchieto,1989).

The values of the finished product quality are influenced by control parameter, such as time of reaction. In (Bayzenberger and Sebastian, 1988) an algorithm for resolving problems of optimal control was proposed in order to maintain the desired mode, minimizing time of reaction.

Also, the dynamics of the processes is significantly affected by the choice of initial temperature of polymerization or degradation (Bitukov et al., 2010), which allows to select initial temperature to determine future dynamics of periodic processes.

Considering the process of degradation of polymers in solution, it should be noted that in the framework of this study, practicability of the process control is shown, being based on choice of degradation time. At the same time, all other process parameters influencing the process in question are to be stabilized.

\section{Conclusion}

In course of system analysis of the processes of obtaining low molecular weight by degradation in a solution, in 
order to find opportunities of controlling these processes, the following main results were obtained.

The main stage of the considered process where the main indicators of the finished product quality are obtained is the process of destruction. Control parameters in this step are reaction time, degree of degradation and the polydispersity index. It is expedient to control these parameters by feeding the initiator to the reaction medium. Other control parameters, such as polymer temperature and mass concentration, are to be stabilized in the vicinity of the maximum allowable value, which does not result in increasing the rate of jellification.

For the purpose of efficient control, molar concentration of the initiator in the reaction mixture should also be stabilized. For this purpose it is proposed to use additional feeding of the initiator into the reaction mass. In this case, as the estimates show, the process of destruction occurs linearly as a function of time. It is shown that implementation of additional initiator is made easier in fractionally equal doses at regular intervals, in this case, same as with continuous addition, the initiator ensures linearity of degradation kinetics over time.

Selection of the initial concentration of the initiator can accelerate or slow down the process of degradation. To implement this method of control, it is required to know the original quality of the polymer (average molecular weight). Thus, knowing the original quality of the polymer, its degree of degradation, it is possible to calculate the initial concentration of the initiator for achieving the final result within the time predetermined by technology.

The work presents theoretical results based on numerical and field experimental studies of polymer degradation kinetics in the laboratory. Definition of the possibility to use the obtained results in industrial conditions requires further experimental work. Thus, a promising direction of development of the research is testing of the obtained control methods in industrial environments.

\section{References}

Bayzenberger, D. zh. A., \& Sebastian, D. Kh. (1988). Principles of Polymerization Engineering. Moscow: Khimiia.

Berlin, A. A., Volfson, S. A., \& Enikolopian, N. S. (1978). The Kinetics of Polymerization Processes. Moscow: Khimiia.

Bitukov, V. K., Tikhomirov, S. G., \& Khaustov, I. A., et al. (2010). Using the Methods of Determining the Polymerization Initial Temperature for Thermoplastic Elastomers Synthesis. Bulletin of VSTA, 44(2), 614-68.

Browarzik, D., \& Koch, A. (1996). Application of Continuous Kinetics to Polymer Degradation. Journal of Macromolecular Science: Pure and Applied Chemistry, 33(11), 1633-1641. http://dx.doi.org/ $10.1080 / 10601329608010928$

Bryk, M. T. (1989). Degradation of Filled Polymers. Moscow: Khimiia.

Cott, B. J., \& Macchieto, S. (1989). Temperature Control of Exothermic Batch Reactor Using Generic Model Control. Industrial \& Engineering Chemistry Research, 28(8), 1177-1184. http://dx.doi.org/10.1021/ie00092a010

Geller, B. E., Geller, A. A., \& Chirtulov, V. G. (1996). Practical Guidance on the Physical Chemistry of Fiber Forming Polymers. Moscow: Khimiia.

Gluett, W. R., Shah, S. L., \& Fisher, D. G. (1985). Adaptive Control of a Batch Reactor. Chemical Engineering Communications, 38(1-2), 67-78. http://dx.doi.org/ 10.1080/00986448508911296

Harish, I. E. (2011). The Synergetic Method of the Synthesis of Control Systems over Chemical Batch Reactors. Proceedings of the SFU. Technical sciences. Special Issue 94. Retrieved October 1, 2014, from http://izv-tn.tti.sfedu.ru/wp-content/uploads/2011/6/9.pdf.

Ivanova, E. D., Dimitrov, I. V., \& Georgieva, V. G. et al. (2012). Non-Isothermal Degradation Kinetics of Hybrid Copolymers Containing Thermosensitive and Polypeptide Blocks. Open Journal of Polymer Chemistry, (2), 91-98. http://dx.doi.org/ 10.4236/ojpchem.2012.23012

Jutan, A., \& Uppal, A. (1984). Combined Feedforward-Feedback Servo Control Scheme for an Exothermic Batch Reactor. Industrial and Engineering Chemistry Process Design and Development, 23(3), 597-602. http://dx.doi.org/10.1021/i200026a032

Kaminsky, V. A., \& Kuznetsov, A. A. (2012). Kinetics of Polymers Degradation by Lawcase. Theoretical Bases of Chemical Technology, 46(4), 453-457. Retrieved from http://elibrary.ru/item.asp?id=17795903 
Kershenbraun, L. S., \& Kittisupakorn, P. (1994). The Use of a Partially Simulated Exothermic (Parsex) Reactor for Experimental Testing of Control Algorithms. Chemical Engineering Research \& Design, 72(1), 55-63.

Koptelov, A. A., Milekhin, Iu. M., \& Baranets, Yu. N. (2012). Simulation of Thermal Decomposition of a Polymer at Random Scissions of C-C Bonds. Russian Journal of Physical Chemistry B, 6(5), 626-633. http://dx.doi.org/10.1134/S1990793112050168

Liptak, B. G. (1986). Controlling and Optimizing Chemical Reactors. Chemical Engineering, (1), 69-81.

Marroquin, G., \& Luyben, W. L. (1973). Practical Control Studies of Batch Reactors Using Realistic Mathematical Models. Chemical Engineering Science, 28, 993-1003. http://dx.doi.org/ 10.1016/0009-2509(73)80001-6

Moiseev, V. V. (1985). Thermoplastic elastomers. Moscow: Khimiia.

Shinskey, F. G., \& Weinstin, J. L. (1965). Dual-Mode Control System for a Batch Exothermic Reactor. In the Proceedings of the Twentieth Annual ISA Conference, Los Angeles, USA.

Sivalingam, G., \& Madras, G. (2004). Thermal Degradation of Poly(vinyl acetate) and Poly(E-caprolactone) and their Mixtures in Solution. Industrial \& Engineering Chemistry Research, 43(7), 1561-1567. http://dx.doi.org/10.1021/ie034115y

Sterling, W. J, Kim, Y. C., \& McCoy, B. J. (2001). Peroxide Enhancement of Poly(r-methylstyrene) Thermal Degradation Industrial \& Engineering Chemistry Research, 40, 1811-1821. http://dx.doi.org/ 10.1021/ie000971n

Tikhomirov, S. G., Khaustov, I. A., \& Popov, A. P. (2013). Kinetics of polymers thermal oxidative degradation: analytical dependence obtaining. Research Journal of International Studies, 10(2), 95-96. Retrieved from http://research-journal.org/wp-content/uploads/2013/11/10-2-17.pdf

Ziff, R. M., \& McGrady, E. D. (1986). Kinetics of Polymer Degradation. Macromolecules, 19, 2513-2519. http://dx.doi.org/10.1021/ma00164a010

\section{Copyrights}

Copyright for this article is retained by the author(s), with first publication rights granted to the journal.

This is an open-access article distributed under the terms and conditions of the Creative Commons Attribution license (http://creativecommons.org/licenses/by/3.0/). 